\title{
Inhibition of Neurotoxicity/Anticancer Activity of Bortezomib by Caffeic Acid and Chlorogenic Acid
}

\author{
REONA MATSUDA ${ }^{1}$, HIROSHI SAKAGAMI ${ }^{2}$, SHIGERU AMANO ${ }^{2}$, YOSUKE IIJIMA ${ }^{3}$, MOTOHIKO SANO $^{4}$, \\ YOSHIHIRO UESAWA ${ }^{5}$, NOBUAKI TAMURA ${ }^{1}$, YOHEI OISHI ${ }^{1}$ and HIROSHI TAKESHIMA ${ }^{1}$ \\ ${ }^{1}$ Division of Geriatric Dentistry, Meikai University School of Dentistry, Saitama, Japan; \\ ${ }^{2}$ Meikai University Research Institute of Odontology (M-RIO), Saitama, Japan; \\ ${ }^{3}$ Department of Oral and Maxillofacial Surgery, Saitama Medical Center, \\ Saitama Medical University, Saitama, Japan; \\ ${ }^{4}$ Division of Applied Pharmaceutical Education and Research, Hoshi University, Tokyo, Japan; \\ ${ }^{5}$ Department of Medical Molecular Informatics, Meiji Pharmaceutical University, Tokyo, Japan
}

\begin{abstract}
Background/Aim: Bortezomib, used for the treatment of multiple myeloma, has been reported to induce potent neurotoxicity. The present study investigated whether eight popular polyphenols inhibit bortezomib-induced neurotoxicity without affecting its anticancer activity. Materials and Methods: Viable cell number was determined with the MTT method. Tumor-specificity was determined by the relative cytotoxicity in human oral squamous cell carcinoma vs. normal oral cells. Neurotoxicity was determined by the relative cytotoxicity in differentiated rat neuronal PC12 cells vs. normal cells. Apoptotic cells were quantified by cell cycle analysis. Results: Bortezomib induced cell shrinkage, disruption of neurites, and accumulation of PC-12 cells in subG1. Only chlorogenic acid and caffeic acid protected PC-12 cells from bortezomib-induced neurotoxicity. Ferulic acid that has one of the two hydroxyl groups replaced by a methoxy group showed a significantly reduced neuroprotective effect. Caffeic acid and the chlorogenic acid also neutralized the anticancer potential of bortezomib. Conclusion: Caffeic acid and the chlorogenic acid may reduce the biological activity of bortezomib by forming a conjugate.
\end{abstract}

Drugs and radiation show bimodal biological activity known as hormesis: beneficial actions at lower concentrations, and adverse actions at higher concentrations $(1,2)$. Previous

This article is freely accessible online.

Correspondence to: Hiroshi Sakagami, Meikai University Research Institute of Odontology (M-RIO), 1-1 Keyakidai, Sakado, Saitama 3500283, Japan. Tel: +81 492792758, e-mail: sakagami@dent.meikai.ac.jp

Key Words: Polyphenol, PC12, SH-SY5Y, NGF, overlay method, neurotoxicity, tumor-specificity, bortezomib, cell cycle, chlorogenic acid, caffeic acid. studies reported adverse effects of anticancer drugs such as cardiotoxicity $(3,4)$, neurotoxicity $(5,6)$, and keratinocyte toxicity $(7,8)$. Bortezomib, a proteasome inhibitor used in the treatment of multiple myeloma, has been reported to induce potent neurotoxicity $(9,10)$. Since polyphenols such as curcumin (11), resveratrol (12), chlorogenic acid $(13,14)$, and $p$-coumaric acid (15) (Figure 1) daily taken from curry, wine, coffee, and various food materials have been reported to show neuroprotective activity, the present study was undertaken to investigate whether these compounds can protect differentiating P12 neuronal cells from the bortezomibinduced insult (9) (Figure 2) without affecting the anticancer activity. Since chlorogenic acid, which consists of caffeic acid and quinic acid, showed the most potent neuroprotective activity among these compounds (Figure 3), caffeic acid (CA), and its related compounds ferulic acid (FA), and isoferulic acid (IFA), and vanillic acid (4-hydroxy-3-methoxybenzoic acid) (VA) (16) (Figure 1), known for their neuroprotective activity (17-19), were also investigated whether they also abrogate the bortezomib-induced neurotoxicity.

\section{Materials and Methods}

Materials. Dulbecco's modified Eagle's medium (DMEM) was obtained from GIBCO BRL (Grand Island, NY, USA); fetal bovine serum (FBS) and actinomycin D from Sigma Aldrich Inc. (St. Louis, MO, USA); chlorogenic acid (CGA), resveratrol (RSV), curcumin, propidium iodide (PI), 3-(4,5-dimethylthiazol-2-yl)-2,5-diphenyltetrazolium bromide (MTT), dimethyl sulfoxide (DMSO) and human recombinant nerve growth factor (NGF) from Wako Pure Chem. Ind. (Osaka, Japan); $p$-coumaric acid, caffeic acid, ferulic acid, isoferulic acid and vanillic acid from Tokyo Chemical Industry Co., Ltd. (Tokyo, Japan); bortezomib (Bmib) from Janssen Pharmaceutical K.K. (Tokyo, Japan); culture plastic dishes and plates (96-well) from Becton Dickinson (Franklin Lakes, NJ, USA). Cell culture. PC12, a cell line derived from a pheochromocytoma of 


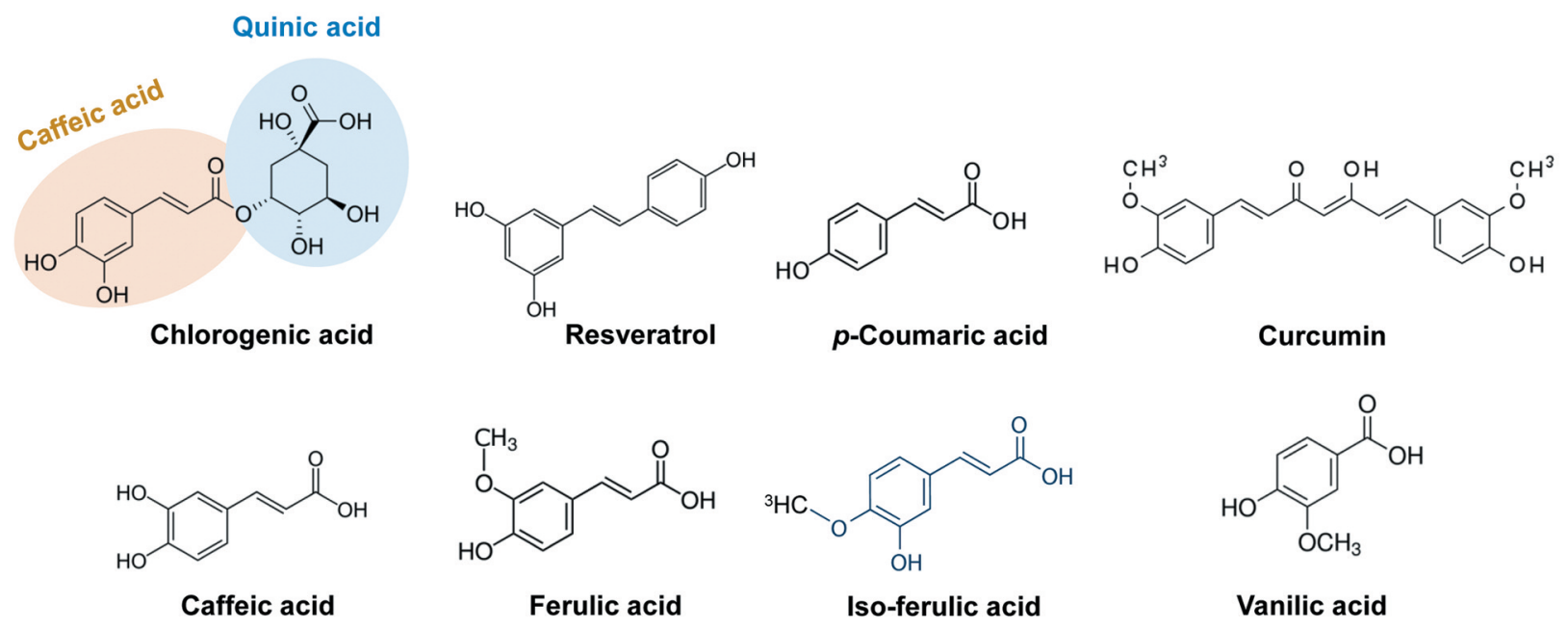

Figure 1. Structures of polyphenols used in this study.

rat adrenal medulla (20), SH-SY5Y, cloned from a human bone marrow biopsy derived line called SK-N-SH $(21,22)$, and human oral squamous cell carcinoma (OSCC) cell lines [Ca9-22 (derived from gingival tissue), HSC-2, HSC-3 and HSC-4 (derived from tongue)] were purchased from Riken Cell Bank (Tsukuba, Japan). Human gingival fibroblast (HGF), periodontal ligament fibroblast (HPLF), and pulp cell (HPC) were established from the first premolar extracted tooth and periodontal tissues of a twelve-year-old girl, according to the guideline of Institutional Board of Meikai University Ethic Committee (No. A0808) (23) and used at 10-18 population doubling level (PDL), considering their limited life span. These cells were cultured at $37^{\circ} \mathrm{C}$ in DMEM supplemented with $10 \%$ heatinactivated FBS and antibiotics, under a humidified 5\% $\mathrm{CO}_{2}$ atmosphere. Differentiated PC12 cells (referred to as dPC-12 cells) expressing extended neurites (Figure 4) were prepared by incubating PC-12 cells for 6 or 7 days in serum-free DMEM medium supplemented with NGF $(50 \mathrm{ng} / \mathrm{ml})$, with fresh NGF-containing medium added on day 3 (24). Cell morphology was checked periodically under a light microscope (EVOS FL; Thermo Fisher Scientific, Waltham, MA, USA).

Determination of viable cell number. Cells were treated for $48 \mathrm{~h}$ with the indicated concentrations of samples, and the viable cell number was determined by the MTT method, as described previously (25). In brief, cells were incubated for $2 \mathrm{~h}$ with MTT reagent at $0.1 \mathrm{mg} / \mathrm{ml}$ (for dPC12 cells) or $0.2 \mathrm{mg} / \mathrm{ml}$ (for other cells). The formazan formed was dissolved with $0.1 \mathrm{ml} \mathrm{DMSO}$ and the absorbance at $560 \mathrm{~nm}$ (that reflects the relative viable cell number) was measured using a microplate reader (Infinite F50R; TECAN, Männedorf, Switzerland).

Calculation of tumor-specificity index (TS). TS was calculated by the following equation: TS=Mean $50 \%$ cytotoxic concentration $\left(\mathrm{CC}_{50}\right)(\mathrm{HGF}+\mathrm{HPLF}+\mathrm{HPC}) /$ mean $\mathrm{CC}_{50}(\mathrm{Ca} 9-22+\mathrm{HSC}-2+$ HSC-3 + HSC-4) (B/A in Table I).

Calculation of neurotoxicity (NT). Neurotoxicity was calculated by the following equation: NT=mean $\mathrm{CC}_{50}(\mathrm{HGF}+\mathrm{HPLF}+\mathrm{HPC}) /$ $\mathrm{CC}_{50}(\mathrm{dPC}-12)(\mathrm{C} / \mathrm{A}$ in Table I).

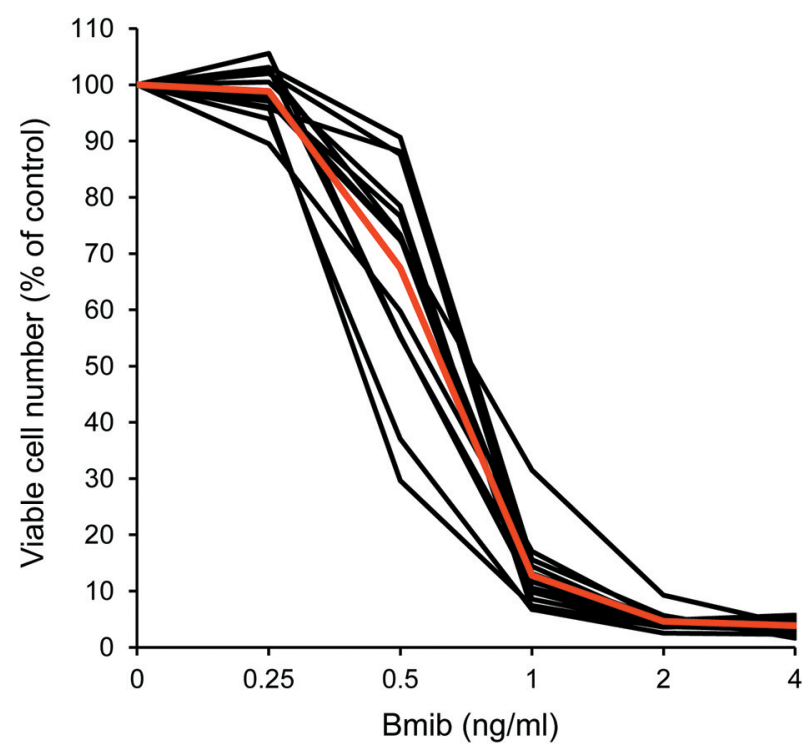

Figure 2. Dose-response curve of growth inhibition by bortezomib. Differentiated PC12 cells (Day 6) were treated for $48 h$ with the indicated concentrations of bortezomib, and then the viable cell number was determined by the MTT method. Each value represents the mean of triplicate determinations. Data of thirteen experiments are shown. Red line represents the mean of 13 experiments.

Cell-cycle analysis. Treated and untreated cells grown in 10-cm cultured dishes (approximately $10^{6}$ cells) were harvested, fixed for $1 \mathrm{~h}$ with paraformaldehyde (1\%), treated for $30 \mathrm{~min}$ with RNase A $(0.2 \mathrm{mg} / \mathrm{ml})$, stained with propidium iodide $(0.01 \%)$ in the presence of $0.01 \%$ NP-40 in PBS (-) to prevent the cell aggregation, filtered through the cell strainers, subjected to cell sorting (SH800 Series; SONY Imaging Products and Solutions Inc., Kanagawa, Japan), and then analyzed with Cell Sorter 


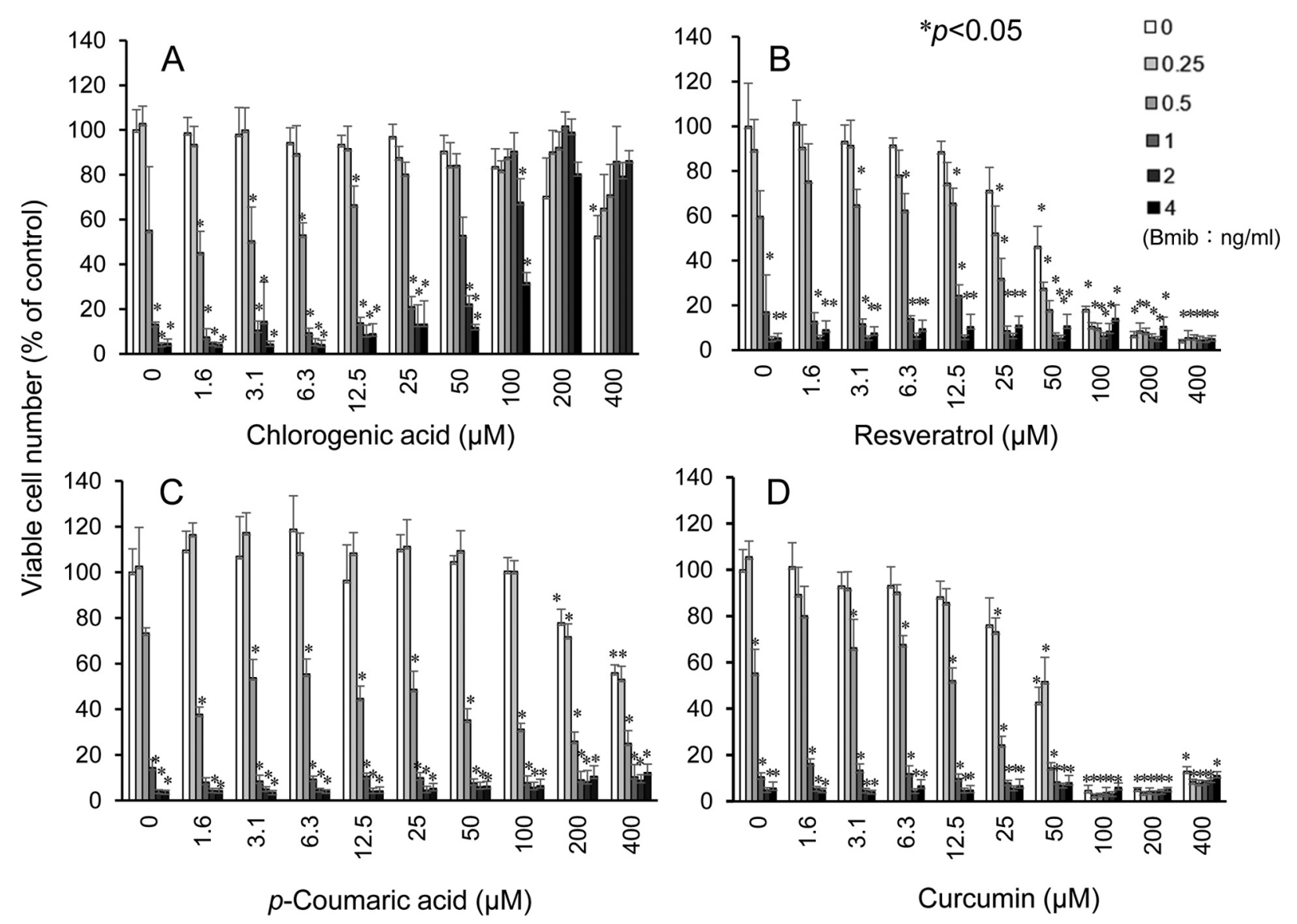

Figure 3. Rescue of bortezomib-induced neurotoxicity by chlorogenic acid. Differentiated PC-12 (dPC-12 cells) were incubated for $48 \mathrm{~h}$ without (control) or with $0.25,0.5,1,2$, or $4 \mathrm{ng} / \mathrm{ml}$ bortezomib (Bmib) in the presence of increasing concentrations of chlorogenic acid (A), resveratrol (B), p-coumaric acid $(C)$ or curcumin $(D)$. The viable cell number was determined with the MTT method, and expressed as \% of control. Each value represents mean \pm S.D. of triplicated determinations. Statistical analysis was performed using one-way ANOVA, followed by Bonferroni's post-hoc test for multiple comparisons. ${ }^{*} p<0.05$ was considered to indicate statistically significant differences.

Software version 2.1.2. (SONY Imaging Products and Solutions Inc.), as described previously (25).

Statistical analysis. Statistical analyses were performed using the Origin pro 2018 software (Origin Lab Corporation, MA, USA). Experimental data are presented as the mean \pm standard deviation (SD) of triplicate determinations. The statistical analysis was performed using one-way analysis of variance (ANOVA) followed by Bonferroni's post-hoc test for multiple comparisons. A value of $p<0.05$ was considered to indicate statistically significant differences.

\section{Results}

Tumor-specificity and neurotoxicity of popular polyphenols. Among four popular polyphenols tested at the initial stage of experiments, resveratrol showed the highest tumor specificity against human oral squamous cell carcinoma cell lines (Ca9-
22, HSC-2, HSC-3, HSC-4) vs. human normal oral cells [gingival fibroblast (HGF), periodontal ligament fibroblast (HPLF), pulp cells (HPC)] (B/A in Table I) $(\mathrm{TS}=5.5)$, followed by curcumin $(\mathrm{TS}=2.0)$, chlorogenic acid and p-coumaric acid (Exp. 1, Table I), caffeic acid, and structurally-related compounds (vanillic acid, ferulic acid, isoferulic acid) $(\mathrm{TS}=1.0)$ (Exp. II in Table I). It should, however, be noted that their tumor-specificity was much lower than that of anticancer drugs, bortezomib (TS=570) (25), doxorubicin $(\mathrm{TS}>34)$ and melphalan (TS=13.3) (Table I). Similarly, neurotoxicity (NT) of these polyphenols against differentiated rat PC-12 cells (dPC-12 cells) (B/C in Table I) $(\mathrm{NT}=1 \sim 9.3)$ was much lower than that of anticancer drugs (NT=428, 30, >111, respectively) (Table I). These results demonstrated that eight candidate compounds showed background levels of anticancer activity and neurotoxicity themselves. 
A
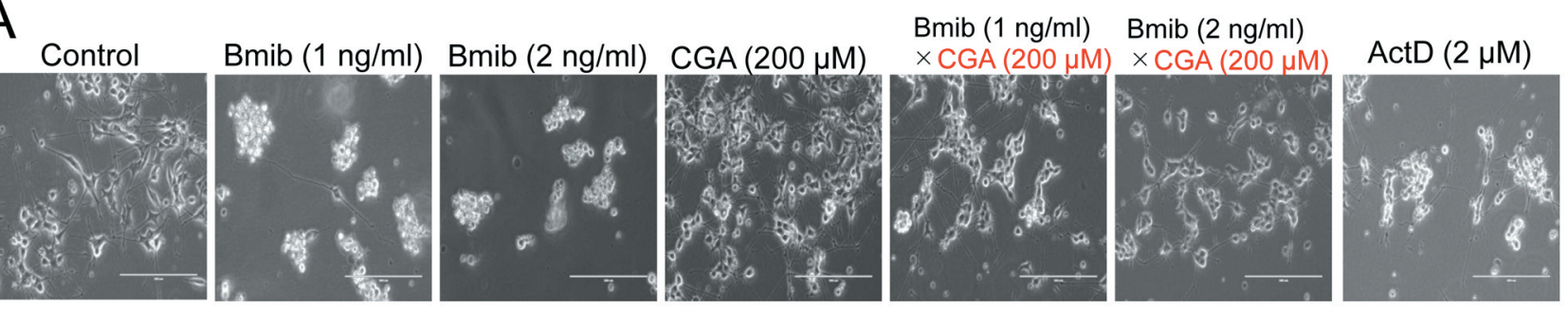

B
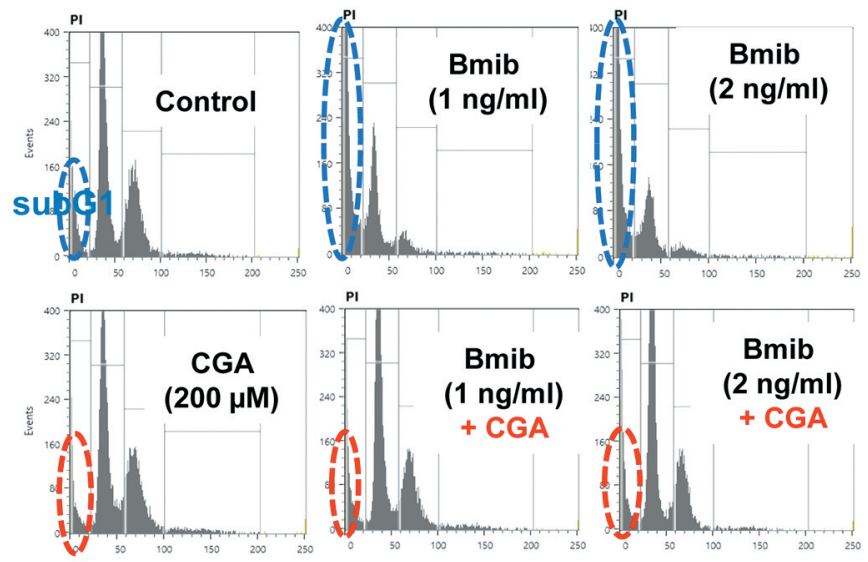

Control

Bmib (1 ng/ml)

Bmib (2 ng/ml)

CGA $(200 \mu \mathrm{M})$

$\operatorname{Bmib}(1 \mathrm{ng} / \mathrm{ml})$

+ CGA $(200 \mu \mathrm{M})$

Bmib (2 ng/ml)

+ CGA $(200 \mu \mathrm{M})$

Act.D $(2 \mu \mathrm{M})$
Distribution (\%)

subG1 G1 S G2/M

$\begin{array}{llll}12.98 & 51.96 & 30.87 & 3.69\end{array}$

$\begin{array}{llll}6^{60.42 *} & 27.45 & 6.98 & 2.61\end{array}$

$\begin{array}{llll}6^{67.88^{*}} & 21.33 & 5.45 & 2.29\end{array}$

$\begin{array}{llll}9.45 & 53.33 & 31.51 & 4.77\end{array}$

$\begin{array}{llll}12.58 & 54.13 & 27.68 & 4.35\end{array}$

$\begin{array}{llll}15.68 & 57.08 & 22.98 & 2.43\end{array}$

$23.10^{*} \quad 37.23 \quad 28.70 \quad 4.95$

$* p<0.05$

Figure 4. Inhibition of Bmib-induced apoptosis by chlorogenic acid in differentiated PC12 cells (Day 6). Differentiated PC12 cells (at Day 6) were treated for $24 \mathrm{~h}$ without (control) or with 1 or $2 \mathrm{ng} / \mathrm{ml}$ bortezomib (Bmib) in the presence or absence of $200 \mu M$ chlorogenic acid (CGA). (A) CGA inhibited the Bmib-induced cell shrinkage and disruption of neurites. (B) CGA inhibited the Bmib-induced accumulation of subG1 population. Actinomycin D (Act.D) $(1 \mu \mathrm{M})$ was used as reference control of apoptosis. Each value represents mean of triplicate assays. The differences between groups were evaluated by ANOVA, followed by Bonferroni's post-hoc test for multiple comparisons. * $p<0.05$ compared to control.

Chlorogenic acid, but not resveratrol, p-coumaric acid, and curcumin, were neuroprotective. Bortezomib dosedependently reduced the viability of dPC-12 cells. At 1 and $2 \mathrm{ng} / \mathrm{m}$ of bortezomib, the viable cell number was reduced to 13 and $5 \%$ of control level, respectively (Figure 2). Chlorogenic acid dose-dependently reduced the neurotoxicity of bortezomib. The protective effect of chlorogenic acid was detected above $50 \mu \mathrm{M}$, increasing up to a plateau level at $200 \mu \mathrm{M}$, where complete inhibition of neurotoxicity was achieved (Figure 3A). On the other hand, resveratrol, $p$-coumaric acid, and curcumin failed to induce such neuroprotective effects throughout the dose ranges from 1.6 to $400 \mu \mathrm{M}$ (Figure 3B, C and D). Bortezomib (1 and $2 \mathrm{ng} / \mathrm{ml}$ ) induced the disruption of neurites, and cell shrinkage (A) and accumulation of subG1 population, (B), more potently than actinomycin D (reference compound of apoptosis inducer) (Figure 4). This was completely reversed by the addition of chlorogenic acid (200 $\mu \mathrm{M})$ (Figure 4).

Caffeic acid, but not other structurally related compound, was neuroprotective. Caffeic acid inhibited the bortezomibinduced neurotoxicity above $25 \mu \mathrm{M}$, with a maximum inhibition achieved at $200 \mu \mathrm{M}$ (Figure 5A). On the other 
Table I. Much lower tumor selectivity and neurotoxicity of chlorogenic acid, as compared with B-mib, melphalan and doxorubicin.

\begin{tabular}{|c|c|c|c|c|c|c|c|c|c|c|c|c|}
\hline & \multicolumn{9}{|c|}{$\mathrm{CC}_{50}(\mu \mathrm{M})$} & \multirow{3}{*}{$\begin{array}{l}\text { Diff. } \\
\text { PC-12 } \\
\text { (C) }\end{array}$} & \multirow[b]{3}{*}{$\begin{array}{c}\mathrm{TS} \\
(\mathrm{B} / \mathrm{A})\end{array}$} & \multirow[b]{3}{*}{$\begin{array}{l}\mathrm{NT} \\
(\mathrm{B} / \mathrm{C}\end{array}$} \\
\hline & \multicolumn{5}{|c|}{$\begin{array}{l}\text { Human oral squamous cell } \\
\text { carcinoma cell lines }\end{array}$} & \multicolumn{4}{|c|}{$\begin{array}{l}\text { Human normal } \\
\text { oral cells }\end{array}$} & & & \\
\hline & $\mathrm{Ca} 9-22$ & HSC-2 & HSC-3 & HSC-4 & $\begin{array}{l}\text { mean } \\
(\mathrm{A})\end{array}$ & HGF & HPLF & HPC & $\begin{array}{l}\text { mean } \\
(\mathrm{B})\end{array}$ & & & \\
\hline \multicolumn{13}{|l|}{$<$ Exp.1> } \\
\hline CGA & $>400$ & $>400$ & $>400$ & $>400$ & $>400$ & $>400$ & $>400$ & $>400$ & $>400$ & $>400$ & $1 *$ & $1^{*}$ \\
\hline RSV & 6.3 & 33.4 & 42.2 & 31.3 & 43.3 & 253 & 228 & 238 & 240 & 25.9 & 6 & 9 \\
\hline$p \mathrm{CA}$ & $>400$ & $>400$ & $>400$ & $>400$ & $>400$ & $>400$ & $>400$ & $>400$ & $>400$ & $>400$ & $1^{*}$ & $1 *$ \\
\hline $\begin{array}{l}\text { CUR } \\
<\text { Exp. 2> }\end{array}$ & 58.4 & 68.3 & 64.5 & 71.8 & 65.8 & 153 & 124 & 122 & 133 & 84.7 & 2 & 2 \\
\hline $\mathrm{CA}$ & $>400$ & $>400$ & $>400$ & $>400$ & $>400$ & $>400$ & $>400$ & $>400$ & $>400$ & 277 & $1^{*}$ & $>1$ \\
\hline VA & $>400$ & $>400$ & $>400$ & $>400$ & $>400$ & $>400$ & $>400$ & $>400$ & $>400$ & $>400$ & $1^{*}$ & $1 *$ \\
\hline IFA & $>400$ & $>400$ & $>400$ & $>400$ & $>400$ & $>400$ & $>400$ & $>400$ & $>400$ & $>400$ & $1^{*}$ & $1 *$ \\
\hline FA & $>400$ & $>400$ & $>400$ & $>400$ & $>400$ & $>400$ & $>400$ & $>400$ & $>400$ & $>400$ & $1^{*}$ & $1 *$ \\
\hline B-mib & & & & & 0.003 & & & & 1.71 & 0.004 & 570 & 428 \\
\hline Melph. & 41.5 & 22.8 & 25.5 & 10.6 & 25.1 & 349 & 319 & 334 & 334 & 11.2 & 13 & 30 \\
\hline DXR & 16.4 & 5.9 & 14.3 & 4.3 & 10.2 & $>400$ & 321 & 321 & $>347$ & 3.1 & $>34$ & $>111$ \\
\hline
\end{tabular}

$\mathrm{CC}_{50}: 50 \%$ Cytotoxic concentration; TS: tumor specificity; NT: neurotoxicity; B-mib: bortezomib; HGF; human gingival fibroblast; HPLF: human periodontal ligament fibroblast; HPC: human pulp cell. ${ }^{*}$ Since several polyphenols show very low cytotoxicity, their $\mathrm{CC}_{50}$ values against oral squamous cell carcinoma cell lines, normal oral cells and differentiated PC12 cells exceeded $400 \mu \mathrm{M}$. This made it very difficult to determine the accurate TS and NT values. Therefore, we presented their TS and NT values as 1.

hand, structurally-related ferulic acid, isoferulic acid and vanillic acid were inactive (Figure 5B, C, D). Induction of cell shrinkage, neurite disruption (Figure 6A) and accumulation of sub G1 population (Figure 6B) by bortezomib were repeatedly observed. Addition of caffeic acid at $200 \mu \mathrm{M}$ inhibited the cell shrinkage and disruption of neurites (Figure 6A) and accumulation of subG1 population, achieving the near complete recovery of viable cells (Figure 6B).

Both chlorogenic acid and caffeic acid also inhibited the cytotoxicity of bortezomib against human neuroblastoma SH-SY5Ycells (Figure 7), as well as rat dPC-12 cells (Figure 3 , Figure 4, Figure 5 and Figure 6).

Chlorogenic acid reduced the anticancer activity of bortezomib. Ideally, chlorogenic acid should only protect from bortezomib-induced neurotoxicity, without affecting its antitumor potential. Bortezomib $(0.25 \sim 4 \mathrm{ng} / \mathrm{ml})$ dosedependently reduced the viability of two human oral squamous cell carcinoma cell lines Ca9-22 (derived from gingiva) (Figure $8 \mathrm{~A}$ and $\mathrm{C}$ ) and $\mathrm{HSC}-2$ (derived from tongue) (Figure $8 \mathrm{~B}$ and $\mathrm{D}$ ), confirming previous findings (25). However, contrary to our expectation, the anticancer activity of bortezomib was also abolished by addition of increasing concentrations of chlorogenic acid (Figure 8A and B) and caffeic acid (Figure 8C and D).

\section{Discussion}

In the American Society of Hematology 2020 annual meeting, the triplet regimen bortezomib, lenalidomide, and dexamethasone was recommended as the standard first-line treatment of multiple myeloma (26). However, as the population of cancer survivors increases, the long-term toxicities of chemotherapeutic agents has been gradually strengthened. More than $30 \%$ of patients receiving bortezomib alone or in combination with other drugs have been reported to develop peripheral neuropathy (bortezomib-induced peripheral neuropathy, BIPN) (27), characterized by neuropathic pain. The pathological mechanism of BIPN may include: (i) demyelination, formation of aggregates, endoplasmic reticulum stress, inhibition of dedifferentiation of Schwann cells, (ii) neuronal dysfunction [hyperactivity of wide dynamic range (WDR) neurons in the spinal dorsal horn, damage of afferent sensory neuron cell bodies located in the dorsal root ganglia (DRG) of the spinal cord, abnormality of ion channel, imbalance of tubulin dynamics, mitochondrial dysfunction, inflammation in DRG neurons], (iii) astrocyte activation, and (iv) macrophage infiltration (10). When human induced pluripotent stem cell-derived sensory neurons were exposed to a clinically relevant dose of bortezomib, alterations in microtubule-associated proteins (especially significant reduction of MAP2c) occurred, suggesting a multifaceted 


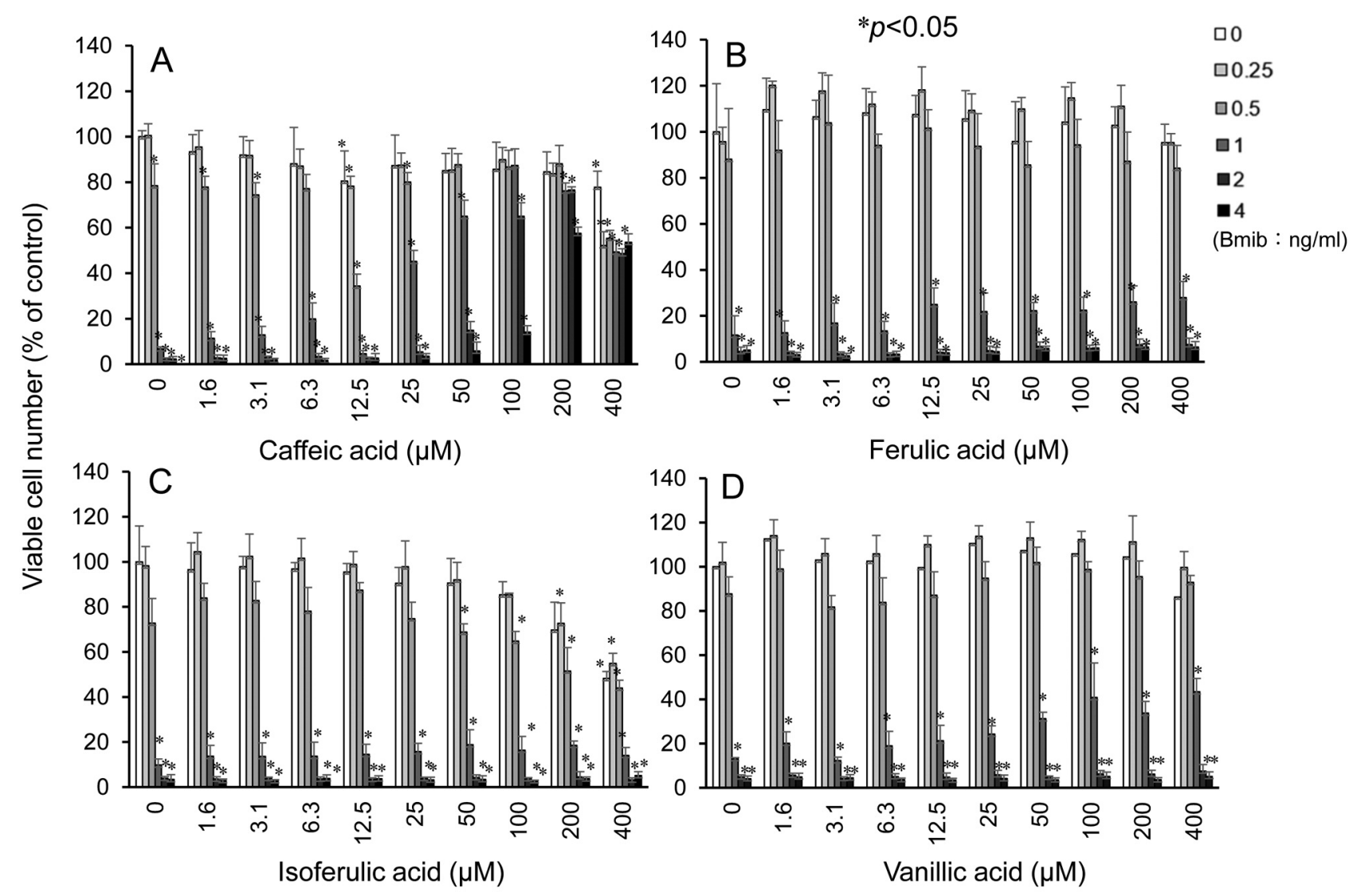

Figure 5. Rescue of bortezomib-induced neurotoxicity by caffeic acid. Differentiated PC-12 (dPC-12 cells) were incubated for $48 \mathrm{~h}$ without (control) or with $0.25,0.5,1,2$, or $4 \mathrm{ng} / \mathrm{ml}$ bortezomib (Bmib) in the presence of increasing concentrations of caffeic acid (A), ferulic acid (B), isoferulic acid $(C)$, or vanillic acid $(D)$. The viable cell number was determined with the MTT method, and expressed as $\%$ of control. Each value represents mean \pm S.D. of triplicated determinations. Statistical analysis was performed using one-way ANOVA, followed by Bonferroni's post-hoc test for multiple comparisons. $* p<0.05$ compared to control.

relationship between bortezomib-induced proteotoxicity and microtubule cytoskeletal architecture (28).

The present study demonstrated that bortezomib induced potent neurotoxicity against differentiated PC-12 neuronal cells $(\mathrm{NT}=428)$ in addition to its potent tumor-specificity ( $\mathrm{TS}=570)$, confirming our previous findings $(9,25)$. Potent neurotoxicity of bortezomib was accompanied by apoptosis phenotypes such as cell shrinkage, disruption of neurites, and accumulation of subG1 population of dPC-12 cells (29-31). However, eight polyphenols tested in this study showed very little neurotoxicity (NT lower than 9) and tumor-specificity (TS lower than 6).

Among the eight test compounds, only chlorogenic acid (an ester formed between caffeic acid and the 3-hydroxyl of Lquinic acid) and caffeic acid, but not other 6 polyphenols tested, protected rat dPC-12 (Figure 3, Figure 4, Figure 5 and Figure 6) and human SH-SY5Y neuroblastoma cells (Figure 7) from potent cytotoxicity of bortezomib. This cannot be explained simply by water solubility, since chlorogenic acid is water soluble $(\log \mathrm{P}=-0.36)$, while other polyphenols (including caffeic acid) and anticancer drugs $(\log \mathrm{P}=1.33 \sim 3.14)$ are hydrophobic (Table II).

Instead, we noticed that the only difference between caffeic acid and ferulic acid is the number of hydroxyl groups. Caffeic acid has two hydroxyl groups in the catechol moiety, while ferulic acid and isoferulic acid have one hydroxyl group with one methoxy group. Under alkaline conditions (such as in the culture medium, $\mathrm{pH}$ 7.4), the boronic acid group of bortezomib and the catechol group of caffeic acid are complexed due to the protonation of the hydroxyl $(\mathrm{OH})$ groups of caffeic acid, creating a high affinity bond between these two molecules (32) (Figure 9). Since dissociation of the conjugate can occur under acidic conditions $(\mathrm{pH}<5)$, it is difficult to prevent the conjugation during incubation in a $5 \% \mathrm{CO}_{2}$ atmosphere, which maintains the $\mathrm{pH}$ at neutral levels. Therefore, chlorogenic acid probably inhibits both neurotoxicity and anticancer activity of bortezomib by conjugation between these two molecules. 
A
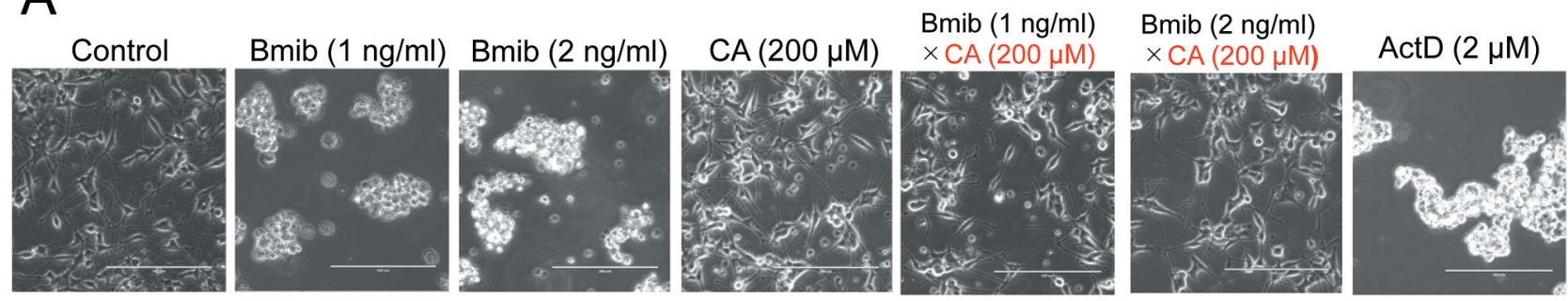

B

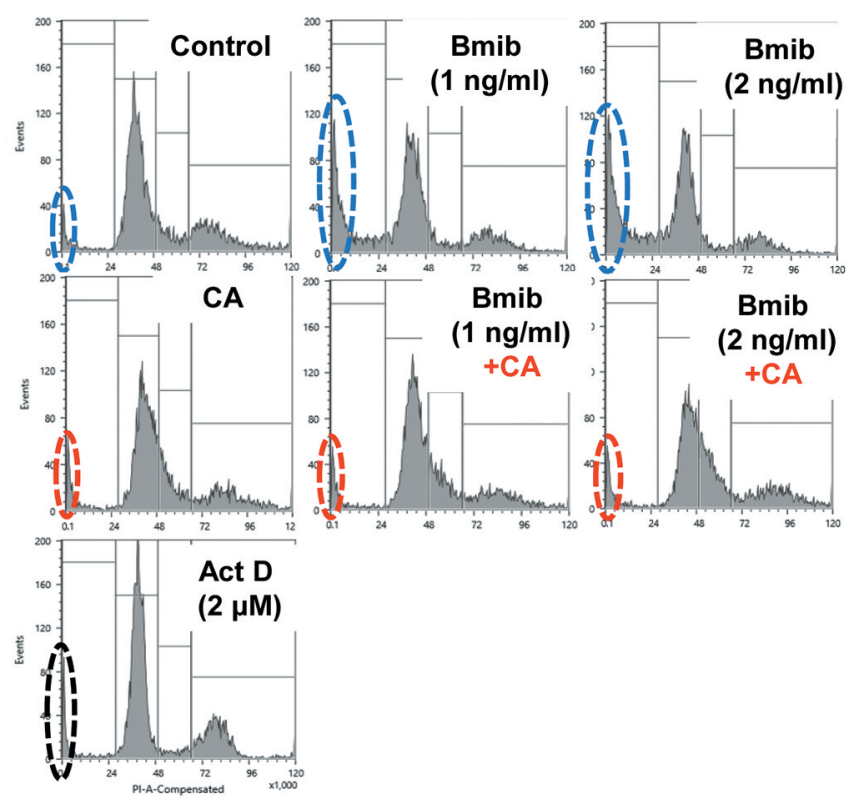

\begin{tabular}{lcccc}
\hline & \multicolumn{4}{c}{ Distribution (\%) } \\
\cline { 2 - 5 } & subG1 & G1 & S & G2M \\
\hline Control & 5.68 & 57.35 & 12.27 & 25.61 \\
Bmib $(1 \mathrm{ng} / \mathrm{ml})$ & $\mathbf{2 6 . 8 7 ^ { * }}$ & 50.66 & 6.83 & 16.43 \\
Bmib $(2 \mathrm{ng} / \mathrm{ml})$ & $\mathbf{3 4 . 9 1 ^ { * }}$ & 46.07 & 6.32 & 13.81 \\
$\mathrm{CA}(200 \mu \mathrm{M})$ & 8.63 & 52.86 & 18.47 & 21.43 \\
$\begin{array}{c}\mathrm{Bmib}(1 \mathrm{ng} / \mathrm{ml}) \\
+\mathrm{CA}(200 \mu \mathrm{M})\end{array}$ & $8.23^{*}$ & 54.74 & 17.89 & 20.40 \\
$\begin{array}{c}\mathrm{Bmib}(2 \mathrm{ng} / \mathrm{ml}) \\
+\mathrm{CA}(200 \mu \mathrm{M})\end{array}$ & $8.67^{*}$ & 51.56 & 18.75 & 22.27 \\
$\begin{array}{c}\text { Act.D }(2 \mu \mathrm{M}) \\
\quad\end{array}$ & $8.48^{*}$ & 61.39 & 4.99 & 25.56 \\
\hline$\quad p<0.05$ & & & &
\end{tabular}

Figure 6. Inhibition of Bmib-induced apoptosis by chlorogenic acid in differentiated PC12 cells (Day 6). Differentiated PC12 cells (at Day 6) were treated for $24 \mathrm{~h}$ without (control) or with 1 or $2 \mathrm{ng} / \mathrm{ml}$ bortezomib (Bmib) in the presence or absence of $200 \mu M$ caffeic acid (CA). (A) CA inhibited the Bmib-induced cell shrinkage and disruption of neurites. (B) CA inhibited the Bmib-induced accumulation of subG1 population. Actinomycin D (Act. D) $(1 \mu \mathrm{M})$ was used as reference control of apoptosis. Each value represents mean of triplicate assays. The differences between groups were evaluated by ANOVA, followed by Bonferroni's post-hoc test for multiple comparisons. * $p<0.05$ compared to control.

There remains to be investigated whether catecholamines, which have two hydroxyl groups, may also inhibit the biological activity of bortezomib.

\section{Conclusion}

Coffee is a very popular daily drink. Coffee beans are rich in chlorogenic acid, which are decomposed to give caffeic acid and quinic acid upon roasting (33). The present study demonstrated that both chlorogenic acid and caffeic acid reduced not only the neurotoxicity but also the anticancer activity of bortezomib by formation of conjugation. Thus, it is necessary to monitor the clinical effects of bortezomib especially on the patients with multiple myeloma who drink coffee.

\section{Conflicts of Interest}

The Authors wish to confirm that there are no known conflicts of interest associated with this publication and there has been no significant financial support for this work that could have influenced its outcome.

\section{Authors' Contributions}

RM and HS performed most experiments of the present study and wrote the manuscript. YI and SA performed the cell cycle analysis. MS and YU reviewed the manuscript.TN, YO and HT provided the interpretation of experimental results and edited the manuscript. All Authors read and approved the final version of the manuscript. 

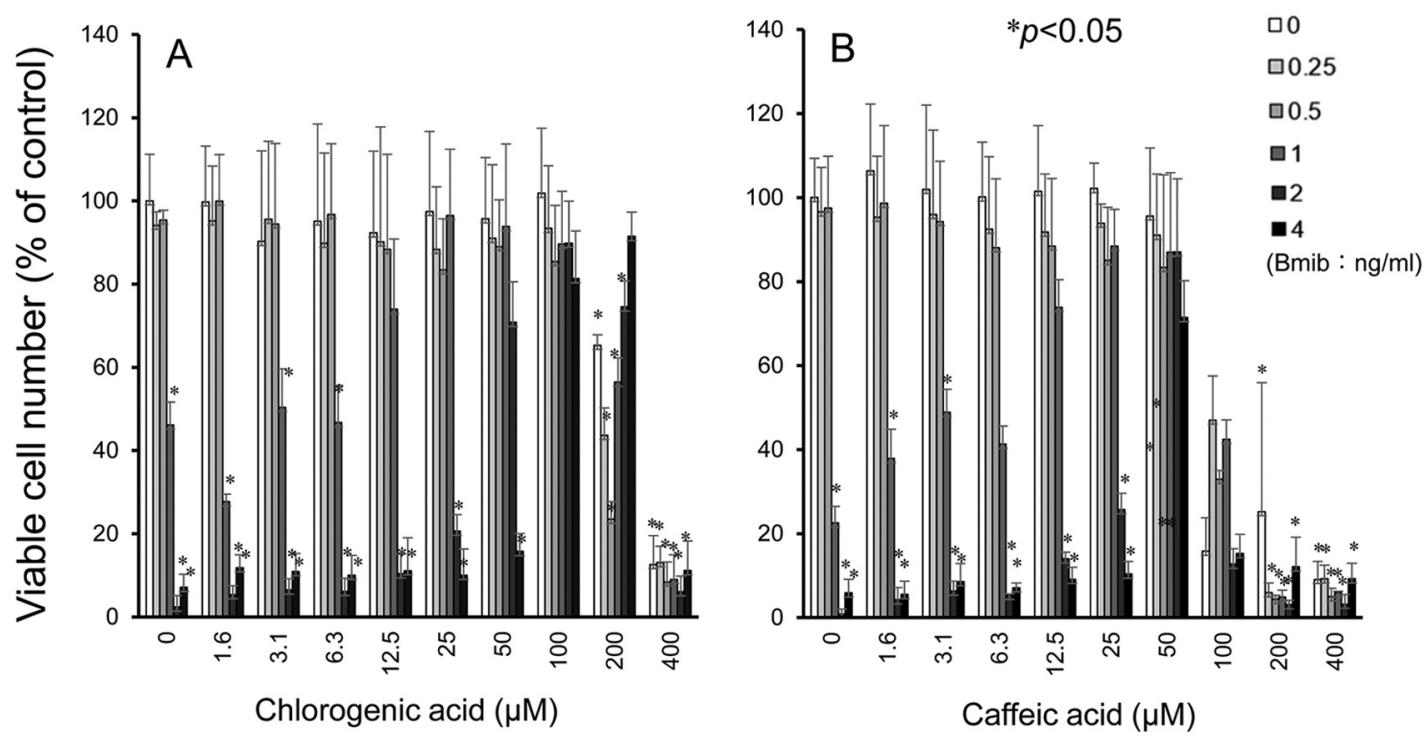

Figure 7. Rescue of bortezomib-induced cytotoxicity against human neuroblastoma SH-SY5Y cells by chlorogenic acid and caffeic acid. SH-SY5Y cells were incubated for $48 \mathrm{~h}$ without (control) or with 0.25, 0.5, 1, 2, or $4 \mathrm{ng} / \mathrm{ml}$ bortezomib (Bmib) in the presence of increasing concentrations of chlorogenic acid (A) or caffeic acid (B). The viable cell number was determined with the MTT method, and expressed as \% of control. Each value represents mean \pm S.D. of triplicated determinations. Statistical analysis was performed using one-way ANOVA, followed by Bonferroni's posthoc test for multiple comparisons. * $p<0.05$ compared to control.
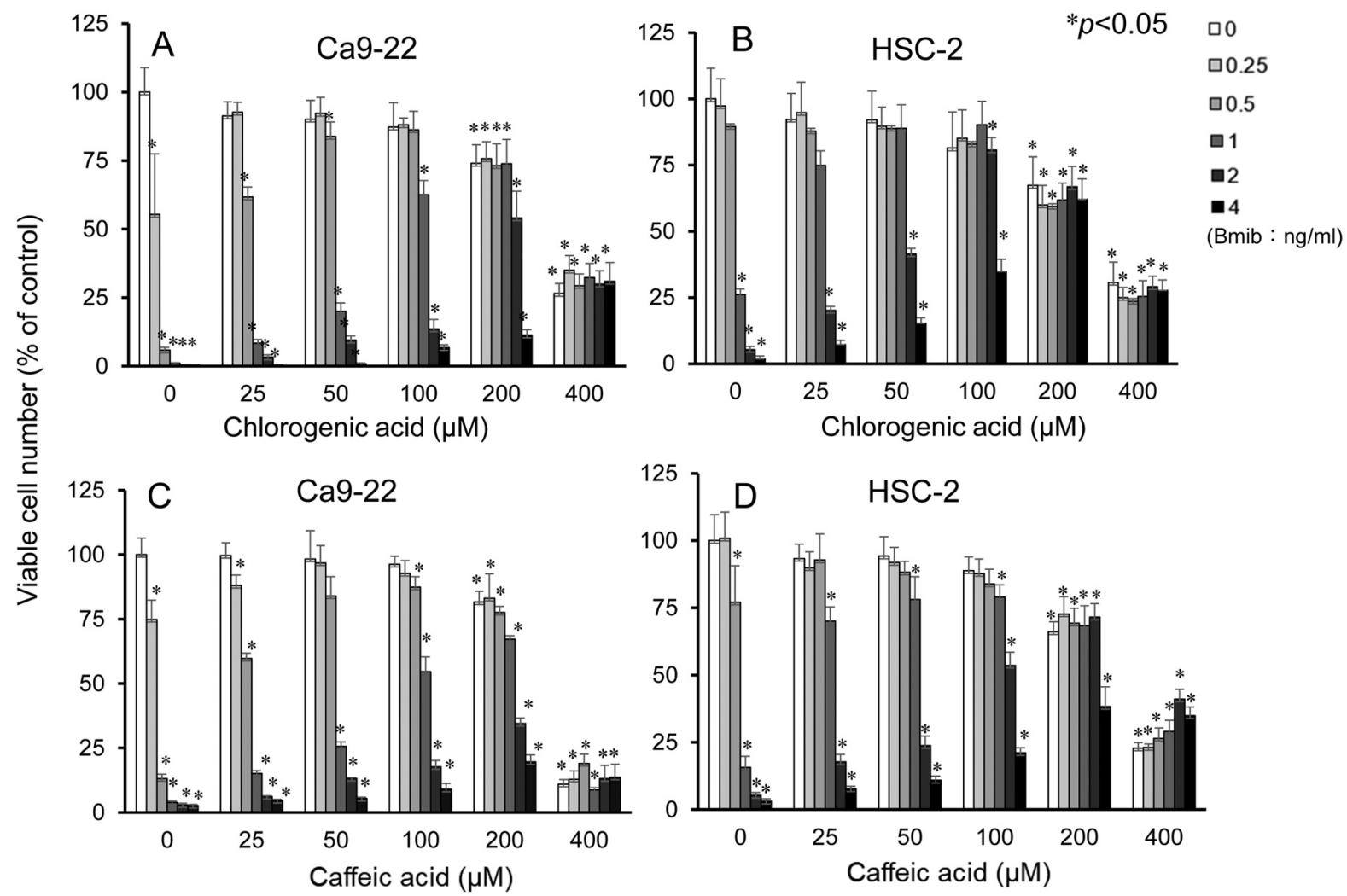

Figure 8. Abrogation of antitumor potential of bortezomib by chlorogenic acid and caffeic acid. Human oral squamous cell carcinoma cell lines Ca9-22 (A, C) or HSC-2 cells $(B, D)$ were incubated for $48 \mathrm{~h}$ without (control) or with 0.25, 0.5, 1,2 or $4 \mathrm{ng} / \mathrm{ml}$ bortezomib (Bmib) in the presence of increasing concentrations of chlorogenic acid $(A, B)$ or caffeic acid $(C, D)$. The viable cell number was determined with the MTT method, and expressed as \% of control. Each value represents mean \pm S.D. of triplicated determinations. Statistical analysis was performed using one-way ANOVA, followed by Bonferroni's post-hoc test for multiple comparisons. ${ }^{*} p<0.05$ compared to control. 

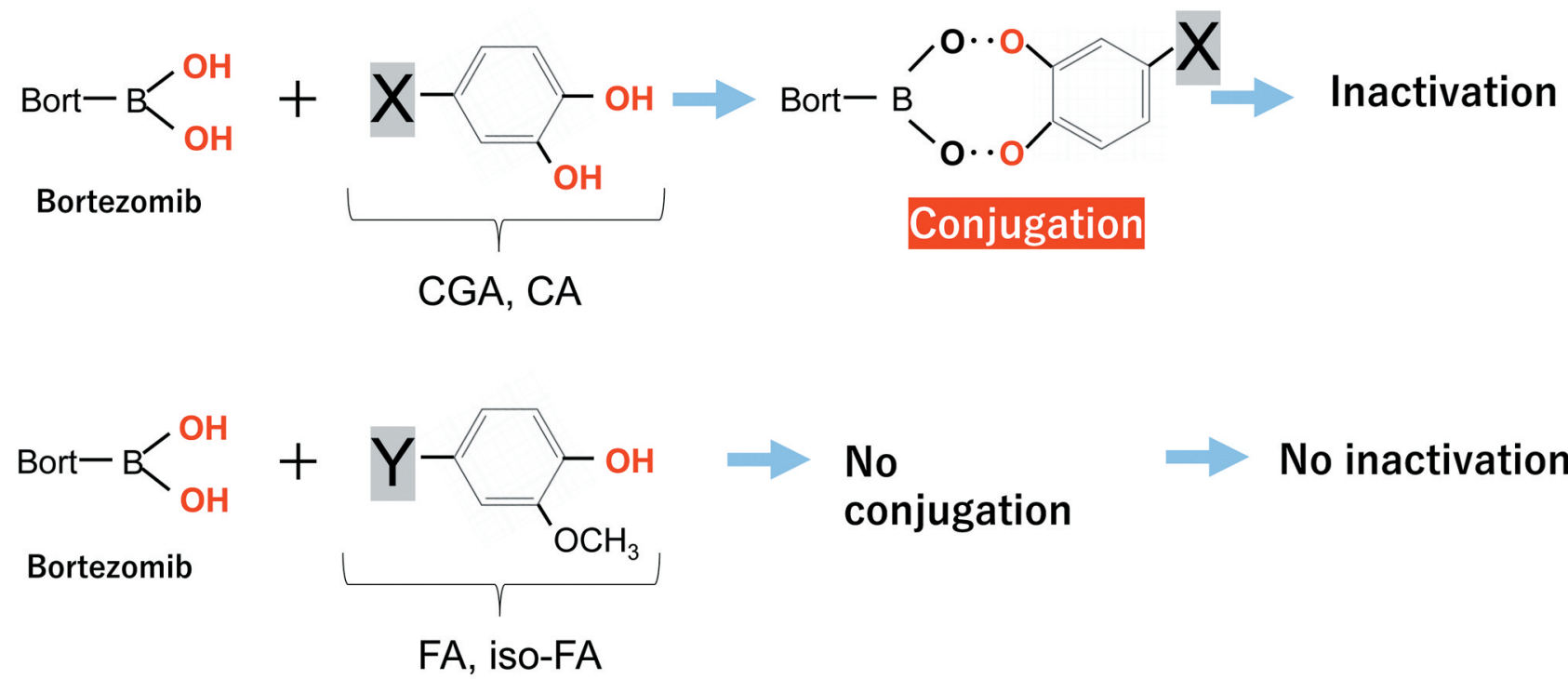

No inactivation

Figure 9. Simple complexation of the boronic acid group of bortezomib and the catechol group of chlorogenic acid or caffeic acid. This figure was produced based on reference 32. Bortezomib can conjugate with chlorogenic acid or caffeic acid, resulting in the inactivation of bortezomib. On the other hand, bortezomib cannot conjugate with ferulic acid or isoferulic acid, and bortezomib is not inactivated.

Table II. LogP value of chlorogenic acid and anticancer drugs (Cited from chemospider).

\begin{tabular}{lc}
\hline & LogP value \\
\hline Chlorogenic acid & -0.36 \\
Resveratrol & 3.14 \\
Curcumin & 2.92 \\
p-Coumaric acid & 1.88 \\
Quinic acid & -1.98 \\
Caffeic acid & 1.42 \\
Ferulic acid & 1.64 \\
Isoferulic acid & 1.64 \\
Vanillic acid & 1.33 \\
Bortezomib & 2.45 \\
Melphalan & 1.79 \\
Doxorubicin & 2.81 \\
\hline
\end{tabular}

\section{Acknowledgements}

The Authors would like to express their deepest gratitude to Dr. Katsuhiro Matsumoto for his help with the statistical processing.

This work was partially supported by KAKENHI from the Japan Society for the Promotion of Science (JSPS, Tokyo, Japan) (16K11519 (HS), 20K09885 (HS), 21K17121 (YI)), and Miyata Research Fund E of Meikai University School of Dentistry (RM), Saitama, Japan.

\section{References}

1 Mattson MP: Hormesis defined. Ageing Res Rev 7(1): 1-7, 2008. PMID: 18162444. DOI: 10.1016/j.arr.2007.08.007

2 Cook R and Calabrese EJ: The importance of hormesis to public health. Cien Saude Colet 12(4): 955-963, 2007. PMID: 17680154. DOI: $10.1590 / \mathrm{s} 1413-81232007000400017$

3 Robinson EL, Azodi M, Heymans S and Heggermont W: Anthracycline-related heart failure: Certain knowledge and open questions: Where do we stand with chemotherapyinduced cardiotoxicity? Curr Heart Fail Rep 17(6): 357-364, 2020. PMID: 32964378. DOI: 10.1007/s11897-020-00489-5

4 Adhikari A, Asdaq SMB, Al Hawaj MA, Chakraborty M, Thapa G, Bhuyan NR, Imran M, Alshammari MK, Alshehri MM, Harshan AA, Alanazi A, Alhazmi BD and Sreeharsha N: Anticancer drug-induced cardiotoxicity: insights and pharmacogenetics. Pharmaceuticals (Basel) 14(10): 970, 2021. PMID: 34681194. DOI: 10.3390/ph14100970

5 Fumagalli G, Monza L, Cavaletti G, Rigolio R and Meregalli C: Neuroinflammatory process involved in different preclinical models of chemotherapy-induced peripheral neuropathy. Front Immunol 11: 626687, 2021. PMID: 33613570. DOI: 10.3389/ fimmu.2020.626687

6 Sałat K: Chemotherapy-induced peripheral neuropathy-part 2: focus on the prevention of oxaliplatin-induced neurotoxicity. Pharmacol Rep 72(3): 508-527, 2020. PMID: 32347537. DOI: 10.1007/s43440-020-00106-1

7 Sakagami H, Okudaira N, Masuda Y, Amano O, Yokose S, Kanda Y, Suguro M, Natori T, Oizumi H and Oizumi T: Induction of apoptosis in human oral keratinocyte by doxorubicin. Anticancer Res 37(3): 1023-1029, 2017. PMID: 28314260. DOI: 10.21873/anticanres.11412 
8 Hung GY, Chen PY, Horng JL and Lin LY: Vincristine exposure impairs skin keratinocytes, ionocytes, and lateral-line hair cells in developing zebrafish embryos. Aquat Toxicol 230: 105703, 2021. PMID: 33249295. DOI: 10.1016/j.aquatox.2020.105703

9 Iijima Y, Bandow K, Amano S, Sano M, Hino S, Kaneko T, Horie $\mathrm{N}$ and Sakagami H: Protection of bortezomib-induced neurotoxicity by antioxidants. Anticancer Res 40(7): 3685-3696, 2020. PMID: 32620607. DOI: 10.21873/anticanres.14357

10 Yan W, Wu Z, Zhang Y, Hong D, Dong X, Liu L, Rao Y, Huang $\mathrm{L}$, Zhang $\mathrm{X}$ and $\mathrm{Wu} \mathrm{J}$ : The molecular and cellular insight into the toxicology of bortezomib-induced peripheral neuropathy. Biomed Pharmacother 142: 112068, 2021. PMID: 34463262. DOI: $10.1016 /$ j.biopha.2021.112068

11 Di Meo F, Margarucci S, Galderisi U, Crispi S and Peluso G: Curcumin, gut microbiota, and neuroprotection. Nutrients 11(10): 2426, 2019. PMID: 31614630. DOI: 10.3390/nu11102426

12 Galiniak S, Aebisher D and Bartusik-Aebisher D: Health benefits of resveratrol administration. Acta Biochim Pol 66(1): 13-21, 2019. PMID: 30816367. DOI: 10.18388/abp.2018_2749

13 abavi SF, Tejada S, Setzer WN, Gortzi O, Sureda A, Braidy N, Daglia M, Manayi A and Nabavi SM: Chlorogenic acid and mental diseases: from chemistry to medicine. Curr Neuropharmacol 15(4): 471-479, 2017. PMID: 27012954. DOI: 10.2174/1570159X14666160325120625

14 Shi X, Zhou N, Cheng J, Shi X, Huang H, Zhou M and Zhu H: Chlorogenic acid protects PC12 cells against corticosteroneinduced neurotoxicity related to inhibition of autophagy and apoptosis. BMC Pharmacol Toxicol 20(1): 56, 2019. PMID: 31500666. DOI: 10.1186/s40360-019-0336-4

15 Lambert de Malezieu M, Ferron S, Sauvager A, Courtel P, Ramassamy C, Tomasi S and Abasq ML: UV-Vis spectroelectrochemistry of oleuropein, tyrosol, and $p$-coumaric acid individually and in an equimolar combination. Differences in LC-ESI-MS ${ }^{2}$ profiles of oxidation products and their neuroprotective properties. Biomolecules 9(12): 802, 2019. PMID: 31795228. DOI: 10.3390/biom9120802

16 Monteiro M, Farah A, Perrone D, Trugo LC and Donangelo C: Chlorogenic acid compounds from coffee are differentially absorbed and metabolized in humans. J Nutr 137(10): 21962201, 2007. PMID: 17884997. DOI: 10.1093/jn/137.10.2196

17 Ayna A, Özbolat SN and Darendelioglu E: Quercetin, chrysin, caffeic acid and ferulic acid ameliorate cyclophosphamide-induced toxicities in SH-SY5Y cells. Mol Biol Rep 47(11): 8535-8543, 2020. PMID: 33040267. DOI: 10.1007/s11033-020-05896-4

18 Kim SR, Kang SY, Lee KY, Kim SH, Markelonis GJ, Oh TH and Kim YC: Anti-amnestic activity of $E$ - $p$-methoxycinnamic acid from Scrophularia buergeriana. Brain Res Cogn Brain Res 17(2): 454-461, 2003. PMID: 12880915. DOI: 10.1016/s0926-6410(03)00161-7

19 Dhanalakshmi C, Manivasagam T, Nataraj J, Justin Thenmozhi A and Essa MM: Neurosupportive role of vanillin, a natural phenolic compound, on rotenone induced neurotoxicity in SH-SY5Y neuroblastoma cells. Evid Based Complement Alternat Med 2015: 626028, 2015. PMID: 26664453. DOI: 10.1155/2015/626028

20 Greene LA and Tischler AS: Establishment of a noradrenergic clonal line of rat adrenal pheochromocytoma cells which respond to nerve growth factor. Proc Natl Acad Sci USA 73(7): 2424-2428, 1976. PMID: 1065897. DOI: 10.1073/pnas.73.7.2424

21 Biedler JL, Helson L and Spengler BA: Morphology and growth, tumorigenicity, and cytogenetics of human neuroblastoma cells in continuous culture. Cancer Res 33(11): 2643-2652, 1973. PMID: 4748425 .
22 Biedler JL, Roffler-Tarlov S, Schachner M and Freedman LS: Multiple neurotransmitter synthesis by human neuroblastoma cell lines and clones. Cancer Res 38(11 Pt 1): 3751-3757, 1978. PMID: 29704.

23 Kantoh K, Ono M, Nakamura Y, Nakamura Y, Hashimoto K, Sakagami $\mathrm{H}$ and Wakabayashi $\mathrm{H}$ : Hormetic and anti-radiation effects of tropolone-related compounds. In Vivo 24(6): 843-851, 2010. PMID: 21164042

24 Sakagami H, Shi H, Bandow K, Tomomura M, Tomomura A, Horiuchi $M$, Fujisawa $T$ and Oizumi $T$ : Search of neuroprotective polyphenols using the "overlay" isolation method. Molecules 23(8): 1840, 2018. PMID: 30042342. DOI: $10.3390 /$ molecules 23081840

25 Iijima Y, Bandow K, Sano M, Hino S, Kaneko T, Horie N and Sakagami H: In vitro assessment of antitumor potential and combination effect of classical and molecular-targeted anticancer drugs. Anticancer Res 39(12): 6673-6684, 2019. PMID: 31810932. DOI: 10.21873/anticanres.13882

$26 \mathrm{Du} \mathrm{J}$ and Zhuang J: Major advances in the treatment of multiple myeloma in American Society of Hematology annual meeting 2020. Chronic Dis Transl Med 7(4): 220-226, 2021. PMID: 34786541. DOI: 10.1016/j.cdtm.2021.08.003

27 Velasco R, Petit J, Clapés V, Verdú E, Navarro X and Bruna J: Neurological monitoring reduces the incidence of bortezomibinduced peripheral neuropathy in multiple myeloma patients. J Peripher Nerv Syst 15(1): 17-25, 2010. PMID: 20433602. DOI: 10.1111/j.1529-8027.2010.00248.x

28 Hrstka SCL, Ankam S, Agac B, Klein JP, Moore RA, Narapureddy B, Schneider I, Hrstka RF, Dasari S and Staff NP: Proteomic analysis of human iPSC-derived sensory neurons implicates cell stress and microtubule dynamics dysfunction in bortezomibinduced peripheral neurotoxicity. Exp Neurol 335: 113520, 2021. PMID: 33129842. DOI: 10.1016/j.expneurol.2020.113520

29 Singh M, Modi A, Narayan G and Singh SK: Benzothiazole derivatives bearing amide moiety: potential cytotoxic and apoptosis-inducing agents against cervical cancer. Anticancer Drugs 27(6): 519-532, 2016. PMID: 26945135. DOI: 10.1097/CAD .0000000000000357

30 Jaganathan SK, Supriyanto E and Mandal M: Events associated with apoptotic effect of $p$-coumaric acid in HCT-15 colon cancer cells. World J Gastroenterol 19(43): 7726-7734, 2013. PMID: 24282361. DOI: 10.3748/wjg.v19.i43.7726

31 Kumar VB, Yuan TC, Liou JW, Yang CJ, Sung PJ and Weng CF: Antroquinonol inhibits NSCLC proliferation by altering $\mathrm{PI} 3 \mathrm{~K} / \mathrm{mTOR}$ proteins and miRNA expression profiles. Mutat Res 707(1-2): 42-52, 2011. PMID: 21185843. DOI: 10.1016/ j.mrfmmm.2010.12.009

32 Aguilar LE, Jang SR, Park CH and Lee KM: Supramolecular caffeic acid and bortezomib nanomedicine: Prodrug inducing reactive oxygen species and inhibiting cancer cell survival. Pharmaceutics 12(11): 1082, 2020. PMID: 33187351. DOI: $10.3390 /$ pharmaceutics 12111082

33 Aree T: Understanding structures and thermodynamics of $\beta$ cyclodextrin encapsulation of chlorogenic, caffeic and quinic acids: Implications for enriching antioxidant capacity and masking bitterness in coffee. Food Chem 293: 550-560, 2019. PMID: 31151647. DOI: 10.1016/j.foodchem.2019.04.084

Received November 27, 2021

Revised December 10, 2021 Accepted December 24, 2021 